\title{
Uma análise estratégica do marketing e o ensino superior privado no Brasil
}

\section{An analysis of strategic marketing and private college institution in Brazil}

\section{Claudia Mara Vicentine}

Doutoranda da Universidad Nacional de Misiones (UNAM), administradora de empresas, Unindus - Universidade da Indústria, Curitiba, PR - Brasil, e-mail: cvicentine@gmail.com

\section{Resumo}

Este estudo apresenta uma análise contextual e estratégica sobre o histórico do ensino superior no Brasil e o uso estratégico do marketing educacional e institucional. Esta pesquisa descritiva do tipo levantamento, com amostra populacional intencional e por acessibilidade, objetivou verificar o que leva alunos a escolherem determinada instituição de ensino superior (IES), em detrimento de outras, para cursarem o ensino superior. Com base nos resultados da pesquisa, será possível ainda identificar quais são os fatores e as ações estratégicas de marketing que mais surtem efeito nos futuros alunos. Os últimos anos têm se caracterizado por mudanças profundas no campo econômico e político que afetaram significativamente as instituições educacionais no que diz respeito à formação adequada do aluno, a estratégias de captação dos alunos, a métodos de ensino, ao uso de tecnologias educacionais, à capacitação dos professores no compromisso com o ensino-aprendizagem em um ambiente agradável, enfim, aos padrões educacionais aplicados aos dias de hoje. O papel do marketing nas IES é criar meios e incentivar projetos que possam gerar novas matrículas, além de manter os alunos que já se encontram na instituição. O importante é que a IES adote um modelo adequado de plano de marketing com vistas às suas necessidades, criando a cultura do planejamento e as ações baseadas neste.

Palavras-chave: Marketing educacional. Instituição de ensino superior. Plano de marketing.

\begin{abstract}
This study presents a contextual analysis and strategic about the history of higher education in Brazil and the use estrategic of educational and institutional marketing course, because the last years have been characterized by deep changes in the economical and political fields, which have significantly altered educational institutions with respect to the adequate formation of students, strategies to recruit students, to the teaching methods and the use of educational technologies. These changes also affected the teachers' capacitation in their commitment with teaching/learning in a pleasant environment, i.e., with the educational standards applied to the present
\end{abstract}


days and to the role of marketing in Els, wich is to create means and to promote projects that may produce new matriculations and keep those students that already are in the institution, motivating them to a matriculation in the following year. What is important is that the El chooses a model that is adequate by marketing plan to its own needs, thus creating the culture planning, as well as actions based on this model.

Keywords: Educational marketing. College institutions. Marketing plan.

\section{Introdução}

Os últimos anos têm se caracterizado por mudanças profundas no campo econômico e político, as quais, por sua vez, afetam significativamente as instituições educacionais no que diz respeito à formação adequada do aluno, aos métodos de ensino, ao uso de tecnologias educacionais, à capacitação dos professores no compromisso com o ensinoaprendizagem em um ambiente agradável, enfim, aos padrões educacionais aplicados até os dias de hoje.

Esta pesquisa descritiva do tipo levantamento, com amostra populacional intencional e por acessibilidade, objetivou verificar o que leva alunos a escolherem determinada instituição de ensino superior (IES) em detrimento de outras para cursarem o ensino superior. Com base nos resultados da pesquisa, será possível ainda identificar quais são os fatores e as ações estratégicas de marketing que mais surtem efeito nos futuros alunos.

Pesquisadores, entre eles Kotler e Fox (1994), vêm se dedicando à busca de caminhos para adaptar a realidade escolar aos novos tempos. Houve um tempo em que a IES oferecia apenas informações, conteúdos teóricos aos seus alunos, pois deveria apenas prepará-los para o cumprimento dos deveres de cidadão e ainda para exercerem uma profissão. Nos dias de hoje, as mudanças ocorridas - e com a própria globalização - fazem com que as IES também despertem para seus novos papéis.

A globalização abre novas portas ao mundo, aos pesquisadores, às pessoas em geral, aos empresários empreendedores, às organizações, às concorrências, às renovações tecnológicas, enfim, a todos que estão inseridos neste contexto atual. Isso tem levado as IES a aceitar as mudanças de forma inovadora e desafiadora, com a aplicação de conhecimentos científicos na solução de problemas práticos.

Procurando conhecer essas expectativas apresentadas pelos alunos, e assumindo os novos papéis que lhe estão sendo impostos por meio de pesquisas e de um acompanhamento efetivo das informações levantadas, a IES poderá atender de uma melhor forma as necessidades do seu públicoalvo. Para isso, precisa reorganizar-se, ser criativa, atualizada, adaptando-se aceleradamente às mudanças propostas e ainda aplicando estratégias de marketing de forma adequada.

Neste sentido, o sucesso da IES hoje está, mais do que nunca, ligado a fatores que vão além da educação tradicional. Não se pode supor que oferecendo uma educação satisfatória, com preços baixos, estarão atendendo aos interesses dos acadêmicos da sociedade, pois isso não é suficiente, exige-se qualidade e inovação!

A IES, a partir do instante em que é considerada uma instituição que mantém contatos com um determinado mercado, estará se comprometendo com a aplicação do marketing para atingir seus objetivos, que nada mais são do que satisfazer de forma rápida e eficiente seu cliente e, consequentemente, obter lucros.

Atualmente, nas IES, esse lucro - essa vantagem - se resume no recrutamento de novos acadêmicos. Para mudar isso e fixar-se com competitividade no mercado, a IES deverá estar aberta às novas táticas de abordagem para atrair e manter alunos com eficácia e qualidade.

O papel do marketing nas IES é criar meios e incentivar projetos que possam gerar novas matrículas, além de manter os alunos que já se encontram na instituição, fazendo com que se matriculem para o ano seguinte.

Os questionamentos são muitos: o que fazer para conquistar mais alunos? Como cativá-los para que permaneçam na escola? Como se relacionar com o mercado? Segundo Cerqueira (1999, p. 36), essas perguntas têm origem num mesmo elemento: a rotina. Como diria Chico Buarque: "todo dia ela faz tudo sempre igual". Essa rotina é aquela que gera um comodismo, aprende-se a fazer de uma maneira e não se faz diferente de jeito nenhum. Repete-se o 
mesmo modelo sempre, "afinal, em time que está ganhando não se mexe”. Pode-se questionar essa premissa? Não se pode esquecer que as razões para o sucesso ontem podem representar exatamente as razões para o fracasso hoje.

O marketing nos dias de hoje é imprescindível em qualquer ramo do mercado e não deve ser utilizado dentro de uma IES somente quando se tem um produto para vender. Pode-se observar um mercado saturado de propagandas, utilizando os mais sofisticados meios para divulgar as vagas abertas para o vestibular, suas atividades, seu método de ensino, seu espaço físico e outros atrativos, mas será que realmente está satisfazendo o público-alvo? Os resultados têm sido satisfatórios?

Kotler (1993) ressalta as más interpretações que as pessoas fazem do marketing, reduzindo-o apenas a um sinônimo de venda e promoção. $\mathrm{O}$ marketing vai além de atrair matrículas, aumentar o número de alunos, pois o bom uso de suas estratégias deve levar a encontrar formas de manter esses clientes, de fazer com que eles se sintam satisfeitos e felizes com o serviço oferecido na instituição.

As IES que abraçam a ideia de implantação de um plano de marketing poderão atingir com sucesso seus objetivos. Tais instituições não devem cansar de atrair novos recursos, motivar os funcionários e professores e achar consumidores.

Segundo Kotler (1993, p. 2), "marketing é um fator-chave de sucesso nos negócios". Ele diz ainda que "é o processo pelo qual indivíduos e grupos obtêm o que precisam e desejam através da troca de produtos e valores", considerando-o fundamental para aqueles que pretendem crescer.

As IES estão mergulhadas em um cenário de inúmeros desafios em uma sociedade embasada nos imediatismos e nas vantagens, são instituições inseridas neste contexto socioeconômico e cultural. Corre-se contra o tempo para encontrar benefícios e tornar-se vencedora no mercado garantindo seu sucesso.

Foram enumeradas por Kotler (1994) quatro contribuições do marketing:

a) maior sucesso no atendimento da missão da instituição;

b) melhorar a satisfação do público da instituição;

c) melhorar a atração de recursos de marketing; d) melhorar a eficiência das atividades de marketing que são sinônimo de organização, de desenvolver trabalhos com embasamento.

A organização terá condições de atender ao mercado-alvo se estiver comprometida com o planejamento de programas e serviços adequados, desenvolvendo programas viáveis, com preços e comunicação também viáveis para informar, motivar e atender o mercado e, consequentemente, o público-alvo.

\section{Histórico do ensino superior privado}

\section{Evolução do ensino superior privado no Brasil}

Pode-se dividir a evolução do ensino superior privado no Brasil, até 1994, em três fases distintas. Segundo Sampaio (1998), o período de 1933 até 1960 corresponde ao período de consolidação do setor privado, na época formado basicamente pelas universidades católicas. No primeiro ano dessa fase, as matrículas no setor privado eram de 14.737, o que correspondia a 43,7\% das matrículas totais. Em 1960, o número de matriculados estava em 19.668, o que representava $44,3 \%$ do total.

Um segundo momento compreende o período entre 1960 e 1980 e foi marcado pelo crescimento de $843,7 \%$ das matrículas no setor privado, enquanto o total de matrículas cresceu 480,3\%. Graças ao seu forte crescimento, o setor privado passou a responder por $62,9 \%$ das matrículas no final da década de 70 . Apesar disso, manteve sua característica de complementaridade em relação à rede pública.

Já a terceira fase vai de 1980 até 1994 e marca a interrupção do crescimento observado na fase anterior, com um aumento de apenas $21 \%$ no total de matrículas no ensino superior em 14 anos, sendo o crescimento de matrículas no setor privado ainda menor: 10\%. Em particular, entre 1980 e 1985 houve uma retração no número de matrículas no setor privado, caracterizando-se por um processo de fusão das instituições do setor privado, reduzindo-se o número de estabelecimentos isolados em contrapartida a uma elevação do número de universidades particulares. Houve, também, queda de $4 \%$ no número total de IES. Também ocorreu, durante o período em questão, a interiorização das IES, bem como a ampliação do leque de carreiras oferecidas. 
Após essas três fases, a partir de 1995, o setor passa por uma grande inflexão: o número de matrículas passa a crescer rapidamente, principalmente as do setor privado, marcando o início de um período que se pode classificar como a quarta fase de evolução. Essa mudança foi consequência, em grande parte, de uma mudança da legislação e das políticas públicas do governo federal para o setor.

Sampaio (1998) discorre sobre a trajetória e as tendências mais recentes do setor privado de ensino superior no Brasil, crendo que três ideias são marcantes: a primeira diz respeito à antiguidade do ensino superior privado no sistema brasileiro; a segunda trata da relação complementar entre os setores público e privado no sistema de ensino superior do País, relação essa que se estabeleceu e se consolidou durante o seu período de expansão; e a terceira refere-se, especificamente, à relação que o setor privado de ensino superior estabelece com o mercado, ou seja, como esse setor organiza a demanda de mercado e reage a ela.

A história do ensino superior privado no Brasil teve início no período Republicano. Até 1900 não existiam mais do que 24 escolas de ensino superior no País (TEIXEIRA, 1989). Naquela época, as instituições particulares que estavam sendo criadas eram, basicamente, de iniciativa confessional católica ou de iniciativa de elites locais que buscavam dotar seus respectivos estados de estabelecimentos de ensino superior.

A consolidação do ensino superior privado ocorreu em um cenário maior de disputa entre as elites laicas e as católicas pelo controle do ensino superior no País, sob a orquestração do ministro Francisco Campos e sob uma moldura legal centralizadora do governo Vargas, como a legislação de 1931 (SCHWARTZMAN; BAUSQUET; COSTA, 1984).

Em 1933, quando foram elaboradas as primeiras estatísticas educacionais, o setor privado já respondia por $64,4 \%$ dos estabelecimentos e por 43,7\% das matrículas de ensino superior. Em 1945, a participação das matrículas do setor privado chegava a quase $50,0 \%$ do total de matrículas do sistema que, à época, contava com cerca de 40 mil estudantes.

Considerando-se o período mais recente, mas ainda anterior à expansão do sistema, que vai de 1945 a 1961, pode-se identificar e sistematizar algumas tendências na criação dos estabelecimentos privados: a) as instituições isoladas mais antigas do período entre 1945-1961 datam de 1951;

b) nessa época tem início uma relativa desconcentração regional das instituições privadas, ou seja, elas começam a ser criadas nos Estados da Bahia, Minas Gerais, Paraná e Goiás;

c) verifica-se, ainda, um processo incipiente de interiorização dos estabelecimentos privados nos Estados de São Paulo, Rio de Janeiro e Rio Grande do Sul; no Estado de São Paulo, em especial, o processo de interiorização chega a atingir sete cidades de médio porte (SAMPAIO, 1998).

Com efeito, a decisão dos estabelecimentos particulares de expandirem-se mediante a criação de cursos voltados para a formação de professores respondia à confluência de três fatores. Em primeiro lugar, a vigência de uma legislação, a de 1931, em que a concepção de universidade baseava-se na existência de um núcleo - a Faculdade de Filosofia, Ciências e Letras - em torno do qual seriam organizadas as demais escolas de formação para profissões tradicionais.

Em segundo, a existência de uma clientela motivada pelas novas oportunidades de acesso ao ensino superior e de carreira no magistério, ou seja, a relativa ampliação da rede de ensino público médio, nos anos 50, acabava funcionando nas duas pontas: de um lado, aumentava a demanda por ensino superior; de outro, alimentava o próprio mercado ocupacional para os egressos dos cursos de Filosofia, Ciências e Letras.

E em terceiro, a estratégia das próprias instituições particulares no sentido de se expandirem sem dispor de muitos recursos financeiros. Cursos dessa natureza tendem a funcionaraté hoje, baseados, sobretudo, em recursos humanos.

Em vinte anos, de 1960 a 1980, as matrículas totais de ensino superior cresceram $480,3 \% \mathrm{e}$ as matrículas no setor privado aumentaram $843,7 \%$. A moldura legal em que se inscreveu essa expansão, sobretudo em seu momento inicial, é a LDB de 1961. Essa Lei foi pragmática: reconhecia a organização do sistema em moldes não universitários.

Os anos de 1968, 1970 e 1971 foram os que apresentaram as maiores taxas de crescimento 
de matrículas. No final da década de 70, o setor privado já respondia por $62,9 \%$ do total de matrículas de ensino superior. Nesses anos, as iniciativas laicas que já dividiam com o segmento confessional a oferta privada de ensino superior desde os anos 50, tornaram-se predominantes, dando uma nova configuração ao sistema.

O setor privado voltado ao atendimento da demanda de massa não se define, portanto, somente por sua predominância no sistema, mas implica também o estabelecimento de uma relação complementar com o setor público ao longo da própria história do ensino superior no País.

Em suma, a expansão do sistema de ensino superior no Brasil caracterizou-se por um ajustamento de funções desempenhadas pelos setores público e privado no período de crescimento da demanda por esse nível de ensino, o que deu origem a essa relação de complementaridade entre ambos os setores. Tal relação é que constitui o fenômeno novo da expansão do sistema de ensino superior desencadeada desde meados dos anos 60 e contínua até meados da década de 80 .

Entre 1980 e 1985, entretanto, ocorreu uma reversão da tendência de crescimento continuado, indicando diminuição no número absoluto e na participação relativa das matrículas do setor privado no conjunto do sistema de ensino superior.

A partir de 1985, constata-se a alternância entre períodos de estabilidade e de redução do número de matrículas do setor privado e de sua participação relativa no sistema de ensino superior (SAMPAIO, 1998).

Entre 1990 e 1994, enquanto as regiões Norte e Centro-Oeste apresentaram as maiores taxas de crescimento percentual das matrículas totais de ensino superior (tanto públicas como privadas) na região Sudeste verificou-se não somente uma diminuição da participação relativa das matrículas privadas no conjunto do sistema, mas uma redução no total de matrículas de ensino superior.

O movimento de transformação dos estabelecimentos isolados em universidades acelerou-se a partir do final dos anos 80. Entre 1985 e 1996, o número de universidades particulares mais do que triplicou, passando de 20 para 64 (SAMPAIO, 1998).

Esse movimento estaria expressando a percepção, por parte da iniciativa privada, que estabelecimentos maiores, com uma oferta mais diversificada de cursos, gozariam de maiores vantagens competitivas na disputa pela clientela de ensino superior. Por isso, os estabelecimentos devem crescer, ampliando o escopo de seus cursos ou ainda criando novas instalações físicas de forma a buscar, inclusive fora de seus domínios já consolidados, novas e diversificadas clientelas.

Outros movimentos importantes e simultâneos que estão acontecendo no setor privado referemse à desconcentração regional e à interiorização de suas instituições. Outra manifestação dessa dinâmica que o setor privado estabelece com o mercado diz respeito ao crescimento acelerado do número de seus cursos e à ampliação do leque de carreiras oferecidas, sobretudo no período 1985 a 1996.

A diversificação do escopo de carreiras, sobretudo nas áreas de Saúde e de Engenharia, tem contribuído também para atenuar a concentração de cursos do setor privado na área de Ciências Sociais Aplicadas, concentração essa característica do próprio desenvolvimento do ensino superior privado no País. Com certeza, essas áreas são chamarizes de novas e abrangentes clientelas. Caso contrário, os estabelecimentos privados não se arriscariam em implementá-las.

\section{Histórico do ensino superior no Paraná}

Em 1913, a Universidade Federal do Paraná (UFPR) começou a funcionar, no início, como instituição particular. Os primeiros cursos ofertados foram Ciências Jurídicas e Sociais, Engenharia, Medicina e Cirurgia, Comércio, Odontologia, Farmácia e Obstetrícia. Após ter fundado a Universidade do Paraná, Victor Ferreira do Amaral - que foi seu primeiro reitor - fez empréstimos e iniciou a construção do prédio central, na Praça Santos Andrade, em terreno doado pela prefeitura.

A história da Universidade Federal do Paraná é marcada por grandes feitos e está muito ligada à história de desenvolvimento do Estado do Paraná. Foi a ousadia e a competência de seus idealizadores, motivados pela sociedade paranaense, que fizeram da UFPR a primeira universidade do Brasil.

Seu início se dá em 1892, quando o político Rocha Pombo lançou na Praça Ouvidor Pardinho a pedra fundamental da Universidade do Paraná. No entanto, por causa do Movimento Federalista o projeto não foi adiante. 
Foi apenas em 1912, quando o Paraná sentiu que precisava de massa crítica para defendêlo, pois seu grupo intelectual era reduzido, que se iniciou novamente o movimento pró Universidade do Paraná. Nessa época, as lideranças políticas também se mobilizaram em prol da criação da Universidade, pois o Paraná havia perdido a região do Contestado para Santa Catarina.

No dia 19 de dezembro de 1912, Victor Ferreira do Amaral e Silva liderou a criação efetiva da Universidade do Paraná. Era uma época próspera da economia paranaense, graças à abundante produção e ao bom comércio da erva-mate. Victor Ferreira do Amaral disse que "o dia 19 de dezembro representava a emancipação política do Estado e deveria também representar sua emancipação intelectual”.

Com a chegada da Primeira Guerra Mundial veio a recessão econômica e as primeiras dificuldades. Entre elas uma lei que determinava o fechamento das universidades, pois o governo federal não recebia bem as iniciativas surgidas de forma independente nos estados. A forma encontrada na época para driblar a lei e continuar funcionando foi desmembrar a instituição em faculdades. Durante mais de trinta anos buscou-se novamente a restauração da Universidade, acontecida no início da década de 50, quando as faculdades foram reunidas e novamente foi formada a Universidade do Paraná. Para essa unificação foi fundamental o apoio da imprensa e da comunidade.

Restaurada a Universidade, a próxima batalha visou à sua federalização. Na época, o reitor Flávio Suplicy de Lacerda mobilizou as lideranças do Estado e em 1950 a Universidade do Paraná tornava-se uma instituição pública e gratuita. Após a federalização, deu-se uma fase de expansão da Universidade.

Após mais de 90 anos de história, a UFPR é, além de símbolo de Curitiba, uma instituição fruto da audácia de seus criadores e que se orgulha de ser a primeira do Brasil e ao mesmo tempo é orgulho para todos os paranaenses.

A Lei Orgânica do Ensino Superior Rivadávia Correia, aprovada pelo Decreto Federal n. 8.659 de 5 de abril de 1911, adotava a liberdade e a desoficialização do ensino no País, retirando da União o monopólio da criação de instituições de ensino superior que fora reforçado após o Decreto n. 3.890 do Código dos Institutos Oficiais de Ensino Superior e Secundário (Epitácio Pessoa) de 1ำ de janeiro de 1901.
Essa escola, criada pela Lei 601 de 8 de outubro de 1909, teve sua origem na Escola Livre de Instrução Militar do Amazonas e passou a chamarse Universidade de Manaus em 13 de julho de 1913 por deliberação de sua congregação. Segundo um histórico da Universidade de Manaus, que abre edição fac-similar da revista Archivos da Universidade de Manaós (1914), publicada pela Universidade do Amazonas em 1989, "a crise que se abateu sobre a Amazônia, após o encerramento do ciclo da borracha, afetou profundamente a Universidade de Manaós que viu seus cursos serem gradativamente desativados, a exceção do curso de Direito [...]” (ESTATUTOS, 1914).

Nessa época, com vistas ao teor da Lei Rivadávia, tem origem também a fundação da Universidade de São Paulo, em 19 de novembro de 1911, e da Universidade do Paraná, em 19 de dezembro de 1912.

Em 18 de março de 1915, o Decreto Federal n. 11.530, da Reforma de Carlos Maximiliano Pereira dos Santos (chamada Lei Maximiliano), novamente exigia que as instituições de ensino superior fossem equiparadas a estabelecimentos oficiais e tivessem cinco anos de funcionamento, em localidade com população superior a 100 mil habitantes. Essa necessidade de equiparação provocou o fechamento da Universidade de São Paulo em 1917.

Já a Universidade do Paraná recorreu, em 1918, à estratégia de reformar seus estatutos, separando as faculdades de Direito, Engenharia e Medicina, e concedendo-lhes autonomia de ensino, mantendo-as, porém, no mesmo edifício, sob uma única diretoria. Os diversos cursos existentes agruparam-se no interior dessas faculdades e foram posteriormente reconhecidos pelo governo federal.

A continuidade de funcionamento de todos os cursos é o caráter que dá à Universidade do Paraná a condição de mais antiga do País, pois esta jamais deixou de funcionar e de lutar por sua restauração, podendo seu "desmembramento temporário" (mas sob uma única direção) ser interpretado como uma mera estratégia para corresponder às exigências legais do momento.

Portanto, desde a conclusão e aprovação de seus estatutos e de sua instalação solene, em 19 de dezembro de 1912, em sessão realizada no edifício do Congresso Legislativo do Estado do Paraná, sob a presidência honorária do Dr. Carlos Cavalcanti de Albuquerque (Presidente do Estado); com sua restauração efetiva, ocorrida em 6 de junho de 1946, 
pelo Decreto-Lei n. 9.323 da União, que reconhecia a Universidade do Paraná, num momento de incentivo à expansão de instituições de ensino superior no País; e, finalmente, com sua federalização, obtida em 4 de dezembro de 1950, pela Lei n. 1.254 do governo federal, a Universidade Federal do Paraná tem o orgulho de poder dizer que é a universidade mais antiga do País, possuindo, inclusive, certificado que comprova a inclusão de seu recorde na edição brasileira do Guinness book - o livro dos recordes de 1995 como primeira universidade brasileira - inaugurada em 1913 (a Universidade do Paraná foi fundada oficialmente em 19 de dezembro de 1912 e iniciou suas atividades de ensino na segunda quinzena de março de 1913, portanto, antes da fundação da Universidade de Manaus, que data de 13 de julho de 1913).

A interiorização do ensino superior desenvolvida no Paraná, entre o final da década de 40 e início da década de 70 , consolidou a estruturação de universidades em três pólos mesorregionais: centro-oriental, sudoeste e norte paranaense, com a implantação da Universidade Estadual de Ponta Grossa (UEPG), da Universidade Estadual do Oeste do Estado (Unioeste), da Universidade Estadual de Londrina (UEL) e da Universidade Estadual de Maringá (UEM), reconhecidas, respectivamente, em 1972.

\section{O mercado de ensino superior}

Semelhante ao que ocorreu com as "empresas ponto com" na internet há alguns anos, o setor do ensino superior privado, mesmo estando em fase de expansão e de melhoria da qualidade, vive um momento de grande especulação financeira, atraindo empresários e investidores descomprometidos com a questão educacional, colocando em risco todo o equilíbrio do sistema.

Comenta-se ainda que a educação superior particular no Brasil sempre foi um bom negócio, mas estava restrita a poucos privilegiados. A burocracia do MEC e a exigência de que as instituições de ensino superior tivessem que ser "sem fins lucrativos" não animava o empresariado brasileiro a investir no setor.

Tudo começou a mudar na gestão de Fernando Henrique Cardoso, com Paulo Renato de Souza no Ministério da Educação. Nessa época, o País presenciou uma abertura sem precedentes no setor educacional privado. Facilitou-se a abertura de novas instituições e foi extinta a obrigatoriedade da instituição ser sem fins lucrativos.

São indiscutíveis as vantagens que a expansão e a abertura do mercado proporcionaram para o setor: atendimento a toda uma demanda reprimida de alunos; acesso ao ensino superior a um maior número de pessoas de classes sociais menos favorecidas; e aumento da concorrência entre as IES, exigindo mais profissionalização, com consequente aumento da qualidade do ensino. No entanto, essa expansão não ocorreu, nem está ocorrendo, de forma equilibrada. Todo setor econômico que se expande demasiadamente rápido, como acontece com o setor da educação superior privada, passa por diversas situações de instabilidade.

Monteiro e Braga (2004) afirmam que no começo, há alguns anos, predominavam parcerias entre educadores aposentados, oriundos das universidades federais, com empresários da construção civil. Unia-se o saber acadêmico com o capital e a facilidade em construir rapidamente as instituições. Depois, começaram a entrar nesse mercado banqueiros, comerciantes, industriais, políticos e apresentadores de televisão, investindo em educação.

No entanto, se a sociedade e o MEC estão conseguindo separar o joio do trigo, em termos de qualidade no ensino, o mesmo não se pode dizer da questão mercadológica. A atual especulação nesse mercado faz com que todos saiam perdendo, tanto as boas IES quanto as "diplomadoras".

Monteiro e Braga (2004) relatam que a demanda de alunos para as IES particulares cresceu $38 \%$ nos últimos três anos. O número de IES cresceu $46 \%$ nos mesmos três anos e o número de vagas oferecidas cresceu $60 \%$ no mesmo período. Como consequência, o número de vagas ociosas cresceu $30 \%$. Ao se juntar o percentual de vagas não preenchidas (quase $40 \%$ ) com o índice de inadimplência (chegando na casa dos 7\% ao ano) e ainda as taxas de evasão (média de mais de $50 \%$ em quatro anos), começamos a perceber que o momento do "estouro da bolha" pode estar próximo.

O número de cursos de graduação registrado é de 16.453 , com um aumento de $14,3 \%$ em relação a 2002. Nas instituições privadas, o crescimento foi de $18 \%$ e, nas públicas, de 7,8\%. Do total de cursos existentes no País, 10.791 (65,6\%) estão no setor privado e $5.662(34,4 \%)$ em instituições 
públicas. Em relação ao número de instituições da educação superior, a concentração é ainda maior no setor privado.

De 1.859 instituições registradas em 2003, 207 são públicas, representando $11,1 \%$, e 1.652 são privadas $(88,9 \%)$. O crescimento registrado em relação ao último ano é de $13,6 \%$. No setor privado, o aumento foi de 14,6\% e, no público, de 6,2\%. Os cursos de graduação tiveram 1.539.859 alunos ingressantes em 2003, considerando todas as formas de ingresso, com crescimento de 4,8\% em relação ao ano anterior. $\mathrm{O}$ número de concluintes foi de 528.102, um aumento de 13,3\% (ASSESSORIA DE COMUNICAÇÃO DO INEP, 2004).

Ao mesmo tempo, o total de matrículas nas IES brasileiras cresceu quase 55\% desde o início desta década, sendo registrados, em 2004, 4.163.733 alunos matriculados - $1.178 .328(28,3 \%)$ no setor público e 2.985.405 (71,7\%) no setor privado. Além disso, o Censo da Educação Superior revela que as mulheres representam 56,4\% desse universo e que enquanto nas IES públicas predominam as matrículas no período diurno $(63,9 \%)$, nas IES privadas há mais alunos matriculados em cursos noturnos $(68 \%)$ (ASSESSORIA DE COMUNICAÇÃO DO INEP, 2004).

Os dados do Censo também demonstram que, em 2004, foram oferecidas 2.320.421 vagas nos processos seletivos das IES brasileiras, $15,9 \%$ a mais que em 2003. Desse total, 308.492 são oriundas do setor público e 2.011.929 do privado. O número de inscrições para concorrer a essas vagas foi 5.053.992 / 2.431.388 em instituições públicas e 2.622.604 em privadas. A relação candidato/vaga no Brasil ficou, portanto, em 2,2, porém nas públicas esse número cresceu para 7,9, enquanto nas privadas caiu para 1,3.

Entretanto, o número de ingressantes foi menor: 1.303 .110 (287.242 nas públicas e 1.015 .868 nas privadas). Constata-se assim que houve 43,8\% (1.017.311) de vagas não preenchidas na educação superior brasileira em 2004. Contudo, especificamente, nas instituições federais essa taxa foi de $0,9 \%$, nas estaduais de $4,7 \%$, nas municipais de $26,4 \%$ e nas instituições privadas de 49,5\%.

Ao se visualizar os dados da Figura 1, pode-se analisar e verificar o salto dado no quesito crescimento do número de IES privadas desde 1980, ou seja, nos últimos 23 anos.

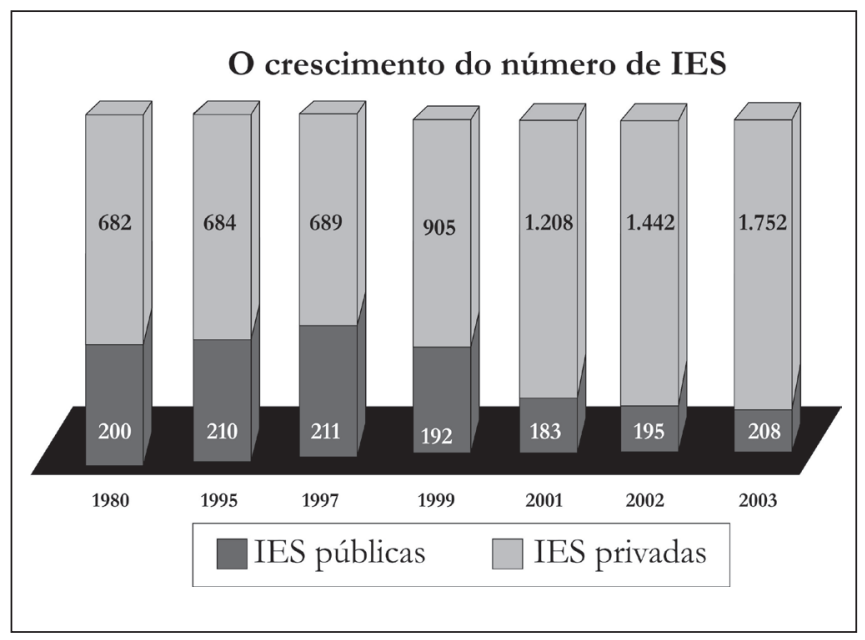

Figura 1 - O crescimento do número de IES no Brasil Fonte: MONTEIRO; BRAGA, 2004.

Para solidificar os dados apresentados na Figura 1, buscaram-se outros números, em que se encontram os seguintes dados: 1.261.901 matrículas na educação superior, só no ano de 2002, em IES privadas numa abrangência nacional, o que acaba por reforçar a análise de crescimento.

De acordo com Monteiro e Braga (2004), os principais jornais do País têm noticiado nas últimas semanas que é crescente o interesse das empresas que administram fundos de investimentos estrangeiros e nacionais em investirem no setor educacional brasileiro. Todas utilizam mais ou menos o mesmo princípio: adquirem parte da instituição, injetam recursos, participam da gestão, esperam o negócio se valorizar e, finalmente, vendem sua parte esperando obter uma alta lucratividade nessa transação.

A questão é que esse processo não será tão fácil como imaginam os empresários da educação. Os administradores dos fundos começam a perceber que o mercado educacional brasileiro ainda apresenta gestão muito amadora, além de pouca transparência contábil, obstáculos quase que intransponíveis para possibilitar o investimento de um fundo. É comum que os mantenedores supervalorizem o valor de suas IES e não aceitem com facilidade os critérios técnicos utilizados nessas avaliações. A outra parte do fato é que já existe mais IES procurando, equivocadamente, "socorro" nos fundos do que empresas administradoras de fundos interessadas em investir na educação (MONTEIRO; BRAGA, 2004). 
Monteiro e Braga (2004) sintetizam que, do mesmo modo que ocorreu com as "empresas ponto com" na internet, o mercado educacional brasileiro continuará sendo um excelente negócio, repleto de oportunidades, mas não terá espaço para amadores, nem para aventureiros que esperam ganhar dinheiro fácil.

\section{Reflexões finais}

À guisa de conclusão do presente trabalho, cabe relembrar os pressupostos anteriormente apresentados, bem como os objetivos que se esperava alcançar. Um dos pressupostos dava conta que as IES não conheciam os fatores e as ações de marketing que mais surtiam efeito junto aos acadêmicos, o que acabou se confirmando em partes, já que os meios de comunicação mais utilizados pela instituição - os cartazes e panfletos - provaram seros mais lembrados por parte dos acadêmicos pesquisados, notando-se que a propaganda em si não está influenciando a tomada de decisão dos futuros universitários.

Quanto aos fatores influenciadores, acredita-se que a participação em feiras, eventos e festas da região com stands e a preocupação com a qualidade de ensino seriam os fatores de atratividade, fato esse já confirmado na opinião dos acadêmicos.

Vários fatores se mostraram mais influenciadores na atratividade, entre eles: propaganda objetiva e transparente; biblioteca diversificada e informatizada; salas de aula confortáveis e arejadas; a realização por parte da instituição de trabalhos comunitários; conhecimento antecipado de alguns professores; e reconhecimento do mercado e da sociedade - salienta-se aqui a questão da qualidade de ensino e ainda o oferecimento de cursos de pós-graduação, ao contrário das forças dispensadas por meio das ações de marketing das instituições, porém, neste item percebe-se um deslize por parte da instituição, pois não há o hábito de sincronizar com os professores, coordenadores e diretores as ações estratégicas futuras que serão desenvolvidas no tocante ao marketing.

Assim, verifica-se que a IES deve direcionar sempre seus esforços de marketing definitivamente para os fatores de atratividade dos acadêmicos, haja vista que a preocupação de utilizar-se da propaganda em períodos sazonais traz efeitos momentâneos, mas não é eficaz na forma cotidiana que visa a consolidar a imagem da instituição como oferecedora de ensino de qualidade.

Como a grande maioria dos acadêmicos tem alguma ocupação profissional, ações promocionais poderão ser desenvolvidas de forma a destacar a importância dos cursos superiores para o crescimento profissional e a realização pessoal.

As propagandas podem estar sendo visualizadas pelos acadêmicos, porém, nem sempre se constatou sua influência efetiva na decisão de opção pela IES, o que faz entender que o problema encontra-se na formulação da mensagem. Textos ou propagandas objetivas e transparentes, que ilustrem, principalmente, a preocupação com a qualidade de ensino - o conhecimento antecipado de alguns professores - associada a uma biblioteca diversificada e informatizada, deverão apresentar mais atratividade, já que foram os fatores considerados mais atrativos por parte dos acadêmicos.

Há também a necessidade de incentivar o público-alvo a visitar a página da instituição na internet, pois esse é um canal de comunicação de baixo custo e que pode apresentar informações importantes para convencer o futuro acadêmico a ingressar na IES, podendo também ser atualizado com grande frequência.

Os fatores influenciadores percebidos pelos acadêmicos, em sua maioria, só podem ser consolidados ao longo do tempo, o que sugere a realização de campanhas fora dos períodos que antecedem o vestibular, ou seja, de caráter permanente, promovendo dessa forma a imagem da instituição.

As matérias jornalísticas provaram ser interessantes e, de certo modo, mais influenciadoras que a própria propaganda. O uso de matérias jornalísticas para a disseminação de informações sobre a qualidade de ensino da IES poderá render grandes frutos, além de auxiliar na formação da imagem da instituição.

Por requerer altos investimentos e pouco retorno em termos de influência do público-alvo, a maneira pela qual a IES está participando de feiras e exposições deverá ser revista, de forma a fazer com que haja o interesse pela visita ao stand e, consequentemente, que informações sobre a instituição possam ser repassadas. A participação em eventos dessa natureza com o intuito de "vender" inscrições para o vestibular deve ser abandonada.

Cartazes e panfletos não podem deixar de ser utilizados pelas IES para a promoção do concurso vestibular. Os demais meios de comunicação devem 
ser utilizados, principalmente para a consolidação da imagem da IES, independentemente do período.

A IES deve criar dotações financeiras claramente definidas para as ações de marketing, pois só dessa forma o departamento de marketing saberá quando e quanto poderá gastar com as ações.

Oaproveitamento de informações colhidas junto aos ex-alunos deve ser melhorado, ou melhor, iniciado, principalmente como ferramenta de retroalimentação já visando à divulgação dos cursos de pós-graduação.

A realização de trabalhos comunitários deverá continuar, porém, a instituição deve preocupar-se, também, em fazer com que isso chegue ao conhecimento do público-alvo.

\section{Referências}

ASSESSORIADE COMUNICAÇÃODO INEP.Censo da educação superior 2004 indica um aumento na eficiência das instituições federais. Disponível em: <http://www.inep.gov.br/imprensa/noticias/censo/ superior/news05_01.htm?>. Acesso em: 30 out. 2006.

ASSESSORIADE COMUNICAÇÃODO INEP. Censo da educação superior. 2004. Disponível em: <http:/ / www.inep.gov.br/imprensa/noticias/censo/superior/ news05_01.htm>. Acesso em: 10 out. 2010.

BRASIL. Lei n. 1.254, de 4 de dezembro de 1950. Dispõe sobre o sistema federal de ensino superior. Diário Oficial [da] República Federativa do Brasil, Poder Legislativo, Brasilia, DF, 4 dez. 1950. Disponível em: < http:/ / www.soleis.adv.br/ ensinosuperiorsistemafederal.htm>. Acesso em: 10 out. 2004.

BRASIL. Lei n. 8.659, de 5 de abril de 1911. Dispõe sobre o sistema federal de ensino superior. Diário Oficial [da] República Federativa do Brasil, Poder Legislativo, Brasília, DF, 5 abr. 1911. Disponível em: <http:// www6.senado.gov.br/legislacao/ListaPublicacoes. action?id=58698 $>$. Acesso em: 19 out. 2010.

BRASIL. Lei n. 601, de 8 de outubro de 1909. Dispõe sobre o sistema federal de ensino superior. Diário Oficial [da] RepúblicaFederativa do Brasil, PoderLegislativo, Brasilia, DF, 5 abr. 1911. Disponível em: <http://portal.ufam.edu. br/index.php/historia >. Acesso em: 19 out. 2010.

BRASIL. Lei n. 11.530, de 29 de junho de 1915. Dispõe sobre o sistema federal de ensino superior. Diário Oficial [da] República Federativa do Brasil, Poder Legislativo, Brasília, DF, 29 jun. 1915. Disponível em: < http:/ / www. pucsp.br/pos/edmat/ma/dissertacao/vera_cristina_santos.pdf>. Acesso em: 19 out. 2010.
BRASIL. Lei n. 9.323, de 23 de julho de 1969. Dispõe sobre o sistema federal de ensino superior. Diário Oficial [da] República Federativa do Brasil, Poder Legislativo, Brasília, DF, 23 jul. 1969. Disponível em: <http:/ / www. al.sp.gov.br/legislacao/norma.do?id=48809>. Acesso em: 19 out. 2010.

ESTATUTOS da Universidade Livre de Manaós a que se refere a Lei n. 601 de 8 de outubro de 1909. Archivos da Universidade de Manaós, ano IV, v. IV, n. 3, p. 69-86, 1914.

CERQUEIRA, W. Endomarketing, educação e cultura para a qualidade. 3.ed. Rio de Janeiro: Qualitymark, 1999.

KOTLER, P.; ARMSTRONG, G. Princípios de marketing. 2. ed. Rio de Janeiro: Prentice-Hall do Brasil, 1993.

KOTLER, P.; FOX, K. F. A. Marketing estratégico para instituições educacionais. 2. ed. São Paulo: Atlas, 1994.

MONTEIRO, C.; BRAGA, R. A bolha especulativa do ensino superior privado. 2004. Disponível em: $<$ http:// www.aprendervirtual.com/ver_noticia.php?codigo $=84>$. Acesso em: 10 out. 2004.

SAMPAIO, H. Breves notas sobre a trajetória e as tendências mais recentes do setor privado de ensino superior no Brasil, São Paulo. 1998. Disponível em: $<$ http:// www.unb.br/labfuturo/helenapalest.htm>. Acesso em: 30 jan. 2006.

SCHWARTZMAN, S. B.;BAUSQUET, M.H.; COSTA, R. V. M. Tempos de Capanema. 1. ed. São Paulo: Edusp; Paz e Terra, 1984.

TEIXEIRA, A. Ensino superior no Brasil: análise e interpretação de sua evolução até 1969. 2. ed. Rio de Janeiro: Fundação Getúlio Vargas, 1989.

Recebido: 29/07/2009

Received: 07/29/2009

Aprovado: 08/08/2009

Approved: 08/08/2009 